three glands are able to stimulate the excretion of phosphate by virtue of their content of "pharmacologically active tissue degradation products".

Although there is not as yet sufficient evidence for the secretion by the thymus or spleen of a hormone effecting phosphate metabolism, the facts summarized above on the results of extirpation of the parathyroid would seem to show that this gland at least secretes a factor necessary for the maintenance of normal phosphate excretion. Although the method of extraction of thymus and spleen used by Stewart and Bowen no doubt yielded a preparation consisting largely of protein, it is of interest that Nitschk $\theta^{7}$ prepared extracts of thymus and spleen having fatty properties which were found markedly to depress the serum inorganic phosphate of dogs. While such material if present as lipoprotein could presumably explain Stewart and Bowen's results, it would appear to have different physico-chemical properties from the phosphate-eliminating extract prepared by us from parathyroid glands. The most important conclusion seems to be that the excretion of inorganic phosphate by the kidney is under the control of a hormone secreted by the parathyroid. Whether the extracts of other glands which have been shown to have activity in this respect contain the same or similar hormones or only non-specific factors remains to be determined. However, it seems certain that whatever the role of the factors derived from other tissues, the secretion of the parathyroid must be quantitatively of considerable importance since extirpation of this gland causes marked effects.

Finally, it should be noted that although, so far as the phosphate effect is concerned, the products of parathyroid and thymus seem to act in the same sense, this is probably not true in relation to their effects on serum calcium. Thus Nitschke? has reported extracts of thymus and spleen insoluble in fatty solvent, which he claimed led to a lowering of serum calcium. It would clearly be of interest to know what effect, if any, Stewart and Bowen's thymus extracts have on serum calcium.

Beryu M. A. Davies A. H. Gordon

National Institute for Medical Research, The Ridgeway, Mill Hill,

London, N.W.7. Dec. 18.

${ }^{1}$ Stewart, G. S., and Bowen, H. H., Endocrinol., 51, 80 (1952).

2 Tepperman, H. M., I'Heureux, M. V., and Wilhelmi, A. E., J. Biol. Chem., 168, 151 (1947).

${ }^{3}$ Biering, A., "Bioassay of Parathyrold Hormones on Rats" (University Press, Aarhus).

- Davies, B. M. A., and Gordon, A. H., J. Endocrin. (in the press).

8 Engfeldt, B., Acta Endocrinol., 5, Supp. 6, 75 (1950).

'Tweedy, W. R., Chilcote, M. E., and Patras, M. C., J. Biol. Chem., 168, 597 (1947).

'Nitschke, A., Z. Ges. Exp. Med., 65, 637 (1929).

\section{Asparagine in Blood Plasma}

Fres asparagine has twice before been reported in animal tissues, namely, in the liver, kidney and spleen of sheep ${ }^{1}$, and, recently, in human urine ${ }^{2}$. The evidence given below shows that it is also present in the blood plasma of both man and the goat : the concentrations are, in fact, comparable to those of many other free amino-acids in blood plasma.

If an amino-acid mixture is analysed by chromatography on 'Dowex-50' resin exactly as described by
Moore and $\mathrm{Stein}^{3}$, but at $20^{\circ} \mathrm{C}$. instcad of $37.5^{\circ} \mathrm{C}$., glutamine and asparagine emerge as a single peak. When a blood plasma dialysate is heated to $100^{\circ} \mathrm{C}$. at $p \mathrm{H} 6 \cdot 5$ for two hours so as to remove glutamine and then subjected to chromatography by this procedure, a ninhydrin-reacting peak still appears in the glutamineasparagine range. If this fraction is heated to $100^{\circ} \mathrm{C}$. with $2 N$ hydrochloric acid for three hours, or incubated at $p \mathrm{H} 7.0$ and $30^{\circ} \mathrm{C}$. for three hours with $1 \mathrm{ml}$. of guinea pig serum, which, unlike other mammalian sera contains an asparaginase enzyme ${ }^{1}$, then, after chromatography, an equivalent amount of ninhydrin-reacting material appears in the aspartic acid range. When the material in the asparagine range is run through a column of 'Dowex-50' with $0.5 \mathrm{~N}$ hydrochloric acid as eluent it emerges as a peak in the same position as known samples of asparagine; if, on the other hand, the material is first hydrolysed with hydrochloric acid, then peaks emerge in the positions of aspartic acid and ammonia. When the fraction in the asparagine range is deionized and subjected to paper chromatography with aqueous phenol, a single spot is obtained in the position of asparagine; if the material is first hydrolysed with hydrochloric acid a spot is obtained in the position of aspartic acid. The material in the asparagine range when reacting with ninhydrin either in solution or after paper chromatography always gives the delayed colour production which is typical of asparagine.

The concentrations of asparagine in blood plasma samples from four men were $1 \cdot 4,1 \cdot 3,1 \cdot 3$ and $1 \cdot 0$ mgm. $/ 100 \mathrm{ml}$. The average of the concentrations in five plasma samples from a single goat was $0.95 \mathrm{mgm} . / 100 \mathrm{ml}$. The concentration of asparagine is thus of the same order as the concentration of many other free amino-acids in plasma.

I am grateful to Dr. D. G. Jamison for his cooperation in obtaining the samples of human blood.

Department of Agriculture, J. M. BARRY

University of Oxford.

${ }^{1}$ Krebs, H. A., Biochem. J., 47, 605 (1950).

2 Stein, W. H., J. Biol. Chem., 201, 45 (1953).

${ }^{8}$ Moore, S., and Stein, W. H., J. Biol. Chem., 192, 663 (1951).

\section{Some Histochemical Observations on Periodic Acid - Amino-Acid Mechanisms}

THE periodic acid Schiff technique has been used histochemically primarily as a means of localizing the 1,2 glycol linkage in tissue sections ${ }^{1}$. It is knnwn, however, that periodic acid is also capable of cleaving the 1,2 hydroxylamino linkage with the production of some aldehyde radicals, and although the exaet reaction mechanism is not understood, it is believed by some to react in a somewhat similar manner with a number of amino-acids possessing structurally neither of these linkages. The amino-acids serine and threonine, as well as the "hydroxylysine" of Van Slyke, fall into the first category, whereas cystine, methionine, tryptophane, glycine, alanine, tyrosine, histadine, aspartic and glutamic acids fall into the latter group ${ }^{2}$. This investigation was initiated to study specifically this phase of the periodic acid Schiff mechanism, and although the results were not conclusive, it was felt that a brief description of the experiments might be of interest to others working in this particular field. 